\title{
Multiple Signaling Pathways Converge to Regulate Bone-Morphogenetic-Protein- Dependent Glial Gene Expression
}

\author{
Justin J. Dore John C. DeWitt Nithya Setty Mareshia D. Donald Esther Joo \\ Melissa A. Chesarone Susan J. Birren \\ Department of Biology and Volen National Center for Complex Systems, Brandeis University, Waltham, Mass., USA
}

\section{Key Words}

Neural crest · GFAP • BMP2 - Kinase pathways · Glial differentiation

\begin{abstract}
A fundamental problem in developmental neuroscience is understanding how extracellular cues link to complex intracellular signaling pathways to drive stage-specific developmental decisions. During the formation of the mammalian peripheral nervous system, bone morphogenetic proteins (BMPs) promote neuronal differentiation. BMPs also maintain the expression of early glial genes such as GFAP, while blocking the acquisition of a mature, myelinating Schwann cell phenotype. We investigated the BMP-activated signaling pathways that contribute to early glial gene expression to address the question of how specific signaling interactions contribute to cell fate decisions in neural crest lineages. Using a neural-crest-derived cell line that exhibits the characteristics of immature Schwann cells, we found that BMP2 promotes GFAP expression using Smad signaling as well as the phosphoinositide-3 kinase (PI3K) and mitogen-activated protein kinase1/2extracellular signal-regulated kinase(MEK1/2/ERK) pathways. The GFAP promoter does not contain known Smad consensus sites, suggesting that Smads
\end{abstract}

may act indirectly to promote GFAP expression. We provide evidence that this indirect effect may be mediated via induction of immediate early genes and the transcription factor Sp1 by demonstrating that these transcriptional regulators are induced by BMP2 and contribute to GFAP promoter activity. These findings demonstrate new roles for intracellular kinase pathways in mediating the effects of BMPs during the early stages of glial differentiation and suggest that differential contributions by signaling and transcriptional networks may contribute to the range of effects of BMPs on neuronal and glial development during the formation of the peripheral nervous system.

Copyright $\odot 2009$ S. Karger AG, Basel

\section{Introduction}

Bone morphogenetic proteins (BMPs) influence many developmental processes including osteogenesis [1], cardiac [2] and neural development [3]. During formation of the central nervous system, BMPs influence both glial and neuronal differentiation. BMPs promote commitment to an astroglial fate among neural progenitor cells derived from embryonic cortex [4], promote astrocytic maturation of GFAP-positive neural progenitor cells [5],

\section{KARGER}

๑) 2009 S. Karger AG, Basel

Fax +41613061234 E-Mail karger@karger.ch www.karger.com www.karger.com/dne
Susan J. Birren

Department of Biology and Volen Center for Complex Systems

415 South Street, Mailstop 008

Brandeis University, Waltham, MA 02454 (USA)

Tel. +1 781736 2691, Fax +1 781736 3107, E-Mail birren@brandeis.edu 
and increase development of the astrocytic lineage in vivo [6]. In addition to these positive effects on astrocytic development, BMPs also negatively regulate the maturation of oligodendrocytes $[7,8]$, the myelinating cells of the central nervous system, by preventing their differentiation and driving early oligodendrocytes to acquire astrocytic properties $[9,10]$. Thus, BMP signaling has complex roles in determining the numbers of different cell types within neural lineages.

BMPs also regulate peripheral nervous system (PNS) development by promoting neuron formation in both the neural crest $[11,12]$ and in postmigratory sensory [13], sympathetic and enteric ganglia [3, 14-17]. Interestingly, BMPs also appear to promote the early stages of peripheral glial development while blocking the acquisition of mature myelinating properties. BMP2 promotes GFAP expression in a neural-crest-derived cell line, but prevents gene expression changes that mark the later stages of glial development [18]. This suggests there are multiple roles for BMPs during PNS formation and raises the question of how BMP signaling drives distinct developmental events in different neural lineages.

One way for BMPs to exert cell-type-specific effects during development is to maintain distinct, intracellular signaling pathways. Signaling via Smad proteins represents the canonical pathway utilized by both BMPs (Smads 1/5/8) and TGF- $\beta$ (Smads 2/3). Additional evidence suggests that non-Smad-associated kinase cascades also contribute to signaling by TGF- $\beta$ family members [19-22]. Non-Smad pathways utilized by BMP2 include Ras/Raf/ERK [23-25] and phosphoinositide-3 kinase (PI3K)/protein kinase B (PKB/Akt) [2, 26, 27]. Interactions with non-Smad kinase pathways can have tissue-specific positive or negative effects on Smad-mediated TGF- $\beta$ family signaling. For example, a direct physical interaction with $\mathrm{PKB}$ prevents Smad3 nuclear translocation in a hepatocyte cell line treated with TGF- $\beta$ [28]. Conversely, ERK activity promotes Smad activation in response to TGF- $\beta$ in human mesangial cells [29]. Thus, a variety of conditions influence the output of BMP signaling pathways, including the cell or tissue type, and possibly the developmental stage. The pathways that contribute to cell fate decisions during early glial development remain to be identified, but a better understanding of the intracellular effectors used by BMPs will help to explain how BMPs exert different effects on distinct PNS lineages.

We previously demonstrated that PI3K, MEK1/2/ERK and Smad signaling contribute to the BMP-dependent induction of the early glial gene GFAP in a neural-crest-de- rived cell line [18]. We have now examined the interactions between these signaling pathways and have defined the transcriptional requirements of BMP2-dependent GFAP expression using both the GFAP promoter and a promoter consisting of Smad consensus sites. We demonstrate that PI3K and MEK1/2/ERK signaling contributes to glial gene activity in response to BMP treatment and may regulate cytosolic Smad1 phosphorylation and nuclear transport dynamics in this neural-crest-derived cell line. In addition, activation of BMP signaling pathways results in the selective induction of several immediate early genes and the transcription factor Sp1. We define a regulatory role for $\mathrm{Sp} 1$ and AP1 sites within the GFAP promoter and suggest a mechanism by which BMPs may influence the early steps of differentiation in glial lineages. Together, these data indicate that the regulation of GFAP expression by BMP2 results from both transcriptional and nontranscriptional mechanisms, and suggest that BMP2 utilizes combinations of different downstream effectors $[30,31]$ that may contribute to the regulation of lineage-specific gene expression during nervous system development.

\section{Materials and Methods}

\section{Plasmid Constructs}

The rat GFAP promoter construct containing $1.9 \mathrm{~kb}$ of upstream promoter sequence directionally subcloned into the pGL3 basic vector (Promega) was kindly provided by Dr. C.E. Finch [32]. A Smad binding element (pSBE) construct containing four tandem repeats of the Smad-responsive sequence CAGACA [33] was provided by Dr. James West (UCHSC). For signal transduction assays, cells were transfected or co-transfected with dominant negative (DN) Ras (S17N) (DN Ras) [34] driven by the Mouse Stem Cell Virus (MSCV) promoter provided by Dr. R. Ren and/or DN pcDNA-PKB (T308A, S473A) (DN PKB) [35] (a gift of Dr. Maria Alexander-Bridges) or DN Smad1 (2SA) (DN Smad1) [36] (a gift of Dr. Steven Harris). Dominant negative pCMV5-Smad5 (DN Smad5) (Addgene, Cambridge, Mass., USA) was generated by substituting serine [36] for glycine 419 . All constructs were cotransfected with Renilla luciferase under constitutive control of the pRL-thymidine kinase promoter (Promega) to control for transfection efficiency. All values are represented as arbitrary relative light units of control and BMP-activated values or as fold increase over the control condition.

\section{Site-Directed Mutagenesis}

Substitution mutations of putative transcription factor binding sites in the GFAP promoter were generated using the QuikChange Site Directed Mutagenesis kit (Stratagene) according to the manufacturer's instructions. Base pair changes were generated in the pGL3b-GFAP AP1 or Sp1 binding sites. The $\Delta$ Sp1 base pair changes were: GGGGCGGG to GGTATAGG. The $\Delta$ AP1 base pair changes were: TGACCATTA to TGGTTGTTA. Primers 
were designed using PrimerX software (bioinformatics.org/primerx/documentation.html). Mutations were confirmed by sequencing using CEQ Dye Terminator Cycle Sequencing (DTCS) (Beckman Coulter, Fullerton, Calif., USA) at the Brandeis Biochemistry Sequencing Core Facility or by GeneWiz, South Plainfield, N.J., USA.

\section{Cell Culture and Transient Transfection}

Neural-crest-derived, $v$-myc-immortalized cells (NCM1) [37] were cultured on fibronectin-coated dishes $(1 \mathrm{mg} / \mathrm{ml})$ in $2 \times$ MAH medium [38] containing $\mathrm{L}^{15 \mathrm{CO}_{2}}$ [39], 10\% FBS, fresh vitamin mix (FVM) and penicillin/streptomycin/glutamine (1:1:2). Cells were maintained under standard tissue culture conditions at $37^{\circ} \mathrm{C}, 5 \% \mathrm{CO}_{2}$. Recombinant BMP2 (Wyeth Pharmaceuticals, Cambridge, Mass., USA) was diluted in medium and used at the indicated final concentration. For transfections, cells were plated at a density of 40,000 cells/well in $2 \times$ MAH media and grown to about $85 \%$ confluence in 24 -well, fibronectin-coated tissue culture dishes (Corning). Twenty-four hours before transfection, cells were placed in serum-free medium consisting of $\mathrm{L}_{15 \mathrm{CO}_{2}, 1 \%}$ BSA, FVM and 1:1:2. Transfections used the Lipofectamine method according to the manufacturer's instructions (Invitrogen). GFAP-luciferase $(0.5 \mu \mathrm{g})$ or pSBE-luciferase $(0.5 \mu \mathrm{g})$ constructs were added with the Renilla luciferase construct $(0.25 \mu \mathrm{g})$. Where indicated, reporter constructs were cotransfected with $0.5 \mu \mathrm{g}$ of DN Ras, DN PKB, DN S1 or DN S5. Additional constructs encoding the full-length GFAP promoter with mutations in the putative Sp1 site, AP1 site or both sites (see above) were also transfected. Five hours after transfection, $10 \mathrm{ng} / \mathrm{ml}$ BMP2 was added to select wells and the cells were harvested $24 \mathrm{~h}$ later. Where indicated, all kinase inhibitors were added to cultures 45 min prior to BMP2 treatment at the following concentrations: PD98,059 (10 $\mu \mathrm{M})$, UO126 $(10 \mu \mathrm{M})$, and LY294,002 $(10 \mu \mathrm{M})$. All transfections were performed in triplicate in a minimum of five independent experiments. At the end of the experiment, cells were lysed and assayed for luciferase activity using the Dual Reporter Assay System (Promega).

\section{Western Blot Analysis}

NCM1 cells were treated with $10 \mathrm{ng} / \mathrm{ml}$ of BMP2 for $0,15 \mathrm{~min}$, $45 \mathrm{~min}, 1.5$ or $5 \mathrm{~h}$ for protein analysis. Cells were then lysed and whole-cell lysates used for immunodetection of Sp1 and AP1 protein expression. For nuclear and cytoplasmic immunoblotting, cells were serum starved for $24 \mathrm{~h}$ prior to simultaneous addition of the kinase inhibitors PD98,056 and LY294,002 (10 $\mu \mathrm{M})$. Cells were treated with BMP2 after $30 \mathrm{~min}$ and nuclear and cytoplasmic fractions were extracted following 30 min of BMP2 treatment using the NE-PER kit according to the manufacturer's instructions (Pierce, Rockford, Ill., USA). Immunoblotting was performed using Rabbit polyclonal GFAP (Sigma), 1:3,000; Mouse $\beta$-actin (Chemicon), 1:15,000; Goat Signal Protein-1 (Santa Cruz) 1:250 or Rabbit Phospho-Smad 1/5/8 (Upstate). All primary immunostaining was performed at room temperature for $2 \mathrm{~h}$ or overnight at $4^{\circ} \mathrm{C}$. Horseradish-peroxidase-conjugated secondary antibodies were applied at a 1:5,000 dilution for $1.5 \mathrm{~h}$ at room temperature. Proteins were detected using Western Lightning Chemiluminescence detection reagent (Perkin Elmer, Boston, Mass., USA). All primary and secondary antibodies were diluted in blocking solution (PBS, 1\% NP40, 10\% donkey serum).

Signaling Pathways Contributing to

BMP-Induced GFAP Activity

\section{Comparative RT-PCR}

RT-PCR was performed as previously described [16]. RNA was isolated using an RNeasy mini kit (Qiagen) from cells cultured in serum-free media, from BMP2-treated cells after 0, 15 min, 1, 6, 12 , or $24 \mathrm{~h}$, from cells treated with BMP2 following kinase inhibitor treatment, or from cells treated with BMP2 for $24 \mathrm{~h}$ in the presence or absence of cycloheximide. RNA was reverse-transcribed using MMLV Reverse Transcriptase (Invitrogen). G3PDH primers were run in triplicate in each individual experiment to match cDNA amounts. All PCRs were performed in triplicate and run on $1.4 \%$ agarose gels with $0.5 \mu \mathrm{g} / \mathrm{ml}$ ethidium bromide. Bands were quantified on a GelDoc system (BioRad) using Molecular Analyst Software (version 2.1.2) and normalized using G3PDH triplicate averages for treated or control samples. Primer sequences were designed using the Whitehead Institute Genome Center Primer3 program [40]. Expression levels of Sp1, c-fos, fos-B, Fra1, Fra2, cJun, Jun-D, and Jun-B are expressed relative to G3PDH and values shown are averages \pm SEM from three or more independent experiments. The following primer sequences were used:

Sp1: 5'ATAGAGGAAGTGGGGGCAAC-3' and 5'-AAGGTGATTGTCTGGGCTTG-3'

c-fos: 5'-AGAGCGGGAGTGGTGAAGAC-3' and 5'-ATTGAGAAGAGGCAGGGTGA-3'

Fos-b: 5'-GGGAACTTTGACACCTCGTC-3' and 5'-TGCTAATGGGCTTGATGACA-3'

Fra1: 5'-GCAGAAACCGAAGAAAGGAA-3' and 5'-TGGAGAAAGGGAGATACAAGG-3'

Fra2: 5'-GCTCTGTCATCAAGCCCATT-3' and 5'-ACTGGTCCCCACTGCTACTG-3'

Jun-D: 5'-TGGAAGAGAGAACGGGAGTG-3' and 5'-ACGGAACAGGAATGTGGACT-3'

c-jun: 5'-CGACCAGAACGATGGACTTT-3' and 5'-GAGAGGTTGGGGGCTACTTC-3'

JunB: 5'-AGGACAAGGTGAAGACACTCAAG-3' and 5' -AGTCAAACACACACACAAACACATC-3'

G3PDH: 5'-ACCACAGTCCATGCCATCAC-3' and 5'-TCCACCACCCTGTTGCTGTA-3'

\section{Statistics}

Significance was calculated using analysis of variance (ANOVA) followed by Fisher's Projected Least Significant Difference post hoc analysis on StatView software, version 4.5 (Abacus Concepts).

\section{Results}

\section{Smads Regulate Both pSBE and GFAP Promoter Activity}

We investigated the requirements for Smad signaling in the activation of the GFAP promoter using DN Smad proteins (DN Smad1 and DN Smad5) and the GFAP promoter [32] to drive luciferase expression in NCM1 cells. NCM1 cells are a neural-crest-derived cell line with the properties of a committed glioblast [37]. Since the GFAP promoter lacks consensus Smad binding sites [41], we compared the actions of the DN Smads at the GFAP promoter to a Smad-responsive synthetic promoter (pSBE-lu- 


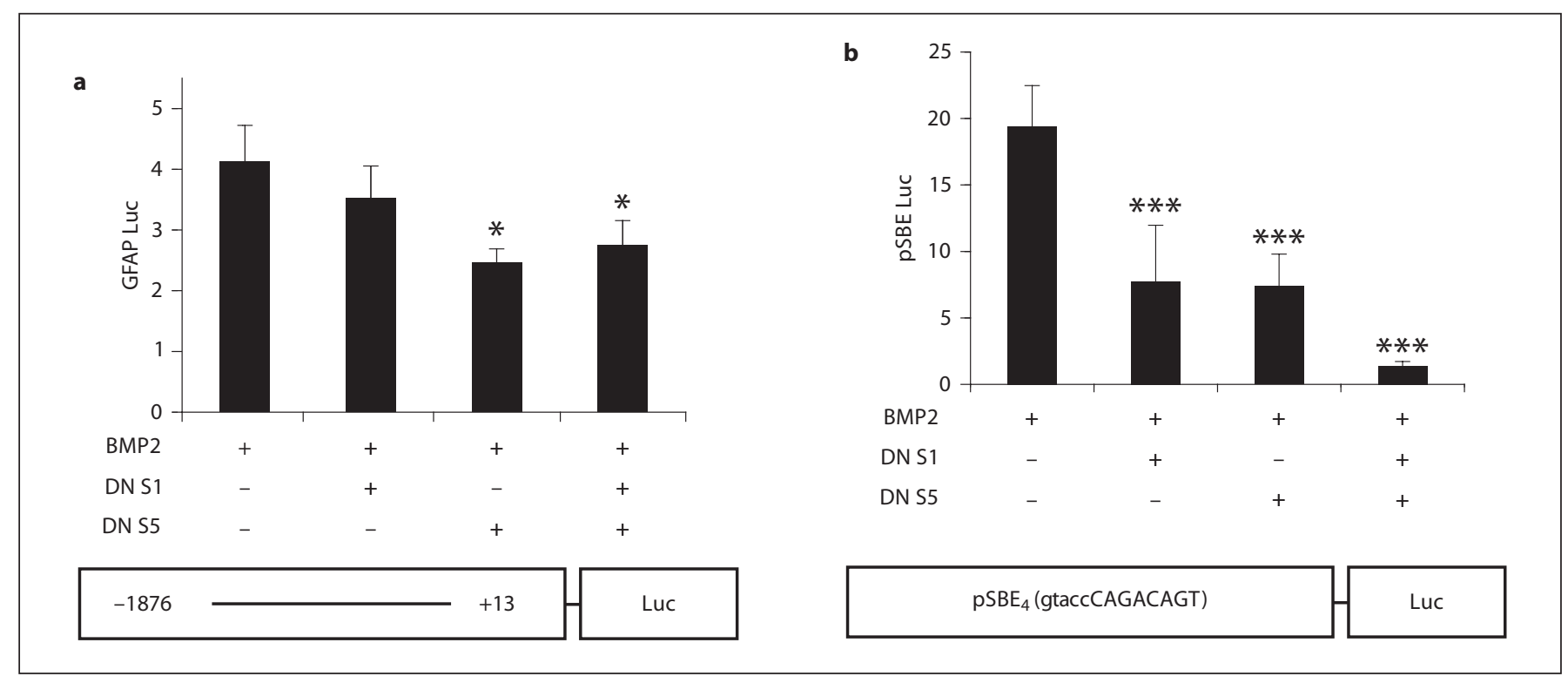

Fig. 1. Smad signaling contributes differentially to BMP2 induction of the GFAP promoter and a synthetic pSBE Smad-responsive promoter. GFAP-luciferase (Luc) or pSBE-luciferase, consisting of tandem repeats of the Smad consensus site GACAGA, was cotransfected into NCM1 cells with DN Smad1 and/or DN Smad5. Cells were treated with $10 \mathrm{ng} / \mathrm{ml} \mathrm{BMP} 2$ for $24 \mathrm{~h}$ and assayed for luciferase activity. All results are corrected using Renilla lucifer- ase values and normalized to untreated, control luciferase values. a DN Smad5 or DN Smad1 with DN Smad5 led to significantly reduced activation of the GFAP promoter $\left({ }^{*} \mathrm{p}<0.05\right)$. b DN Smad 1 or DN Smad 5, singly or in combination, led to a dramatic and significant reduction in pSBE promoter activity $\left({ }^{* *} \mathrm{p}<0.001\right)$. Results represent the combination of 6-12 independent experiments performed in triplicate \pm SEM. ciferase) that contains tandem repeats of the Smad consensus sequence CAGACA. BMP2 treatment of GFAP-luciferase-expressing NCM1 cells resulted in a four-fold induction (fig. 1a). DN Smad1 did not significantly inhibit this BMP2-induced GFAP promoter activity. DN Smad5 and the combination of DN Smad1 with DN Smad5 led to a partial but significant reduction in BMP2-dependent GFAP expression (fig. 1a). In contrast to the GFAP-luciferase construct, BMP2 treatment resulted in a robust 20 fold induction of the pSBE promoter. Inhibition of the BMP2 response was significant for either DN Smad1 or DN Smad5 alone, with almost complete inhibition resulting from combined transfection of the two DN constructs (fig. 1b). This suggests that Smads contribute to the regulation of the early glial gene GFAP, but cannot account fully for the BMP-dependent regulation of this promoter.

\section{$P K B$ and Ras Influence Both GFAP and PSBE \\ Promoter Activity}

We previously demonstrated that pharmacological inhibition of both PI3K and MEK1/2/ERK resulted in a significant decrease in BMP-induced GFAP promoter activation [18]. We have now investigated the promoter specific- ity of these non-Smad kinase pathways by comparing the requirement for the PI3K and MEK1/2/ERK pathways in the activation of the GFAP and the Smad consensus-containing SBE promoter (fig. 2). We measured BMP2 responses in cells expressing DN signaling proteins in the $\mathrm{PI} 3 \mathrm{~K}$ and MEK1/2/ERK pathways. NCM1 cells were transfected with the pSBE promoter-luciferase construct and DN Ras to target the MEK1/2/ERK pathway, and/or DN protein kinase $\mathrm{B}$ (PKB, Akt) to target $\mathrm{PI} 3 \mathrm{~K}$ signaling [42] (fig. 2a, c). These DN constructs have been used extensively to effectively inhibit signaling from these pathways in a variety of systems [43-46]. Inhibition of the PI3K pathway with DN PKB, or coexpression of DN PKB with DN Ras, resulted in a significant reduction in BMP2-dependent activity at the Smad consensus pSBE promoter whereas DN Ras alone had no effect (fig. 2a). To further confirm the involvement of the PI3K pathway in pSBE promoter activation, we also used pharmacological inhibitors of these pathways. Again, a significant reduction in BMP2-dependent pSBE activity was observed only in conditions in which PI3K was inhibited (fig. 2b), suggesting that the PI3K pathway plays a role in promoting the activity or availability of Smad interactions at the pSBE elements. 


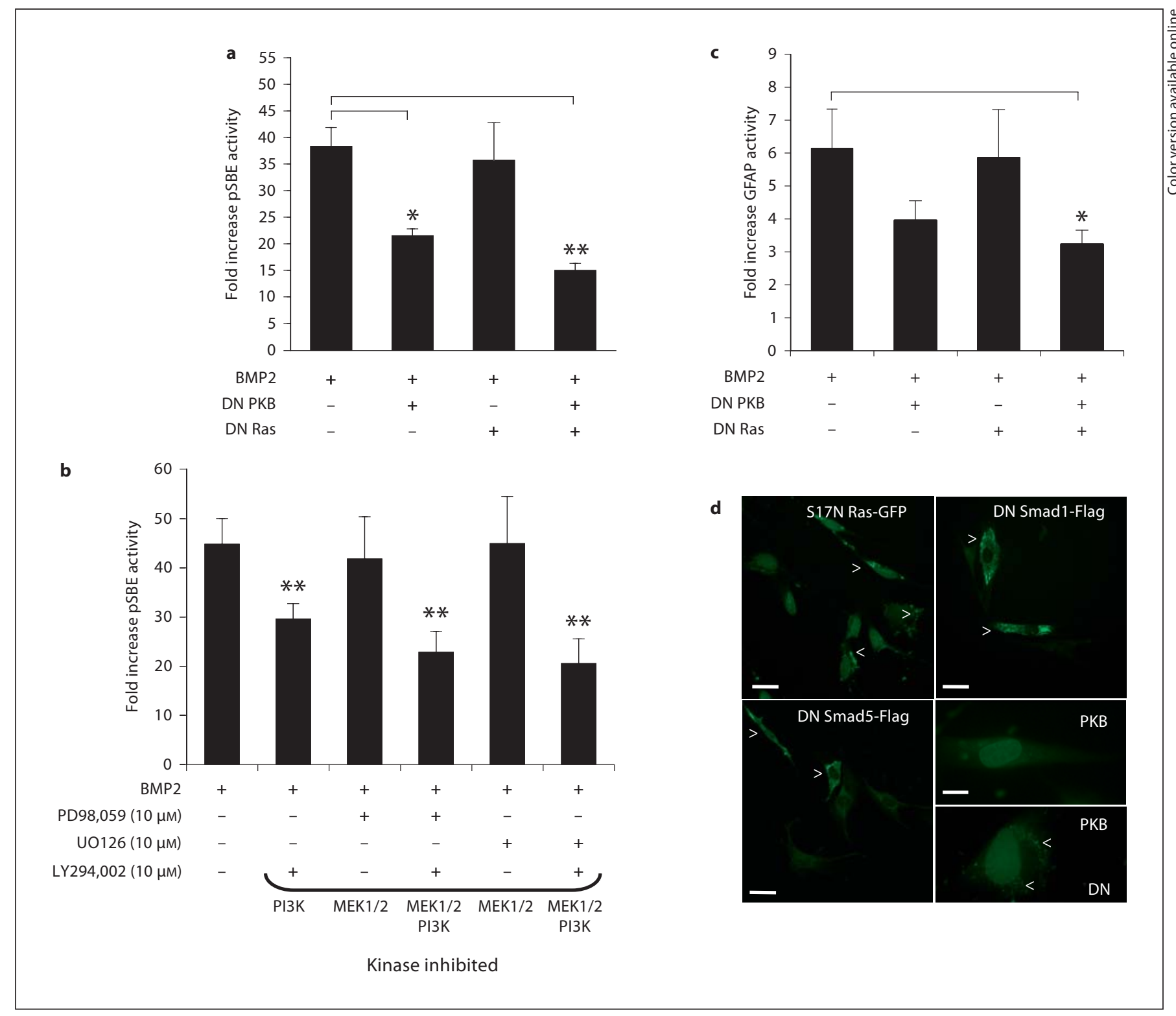

Fig. 2. Protein kinase $B(P K B)$ signaling contributes to $B M P 2$ induction of the GFAP and the pSBE promoters. a NCM1 cells were transfected with the pSBE promoter-luciferase construct in addition to constructs encoding DN Ras and/or DN PKB. Cotransfection of pSBE with DN Ras did not reduce pSBE promoter activity following BMP2 treatment. Cotransfection of DN PKB, or DN PKB with DN Ras led to statistically significant $\left({ }^{*} \mathrm{p}<0.05\right.$, $\left.{ }^{* *} \mathrm{p}<0.01\right)$ reductions in BMP2-stimulated pSBE activity. b NCM1 cells were cotransfected with the pSBE construct and treated with $10 \mathrm{ng} / \mathrm{ml} \mathrm{BMP} 2$ for $24 \mathrm{~h}$ following a 45 -min pretreatment with PD98,059 $(10 \mu \mathrm{M})$ or UO126 $(10 \mu \mathrm{M})$, inhibitors of MEK1/2/ERK or the PI3K inhibitor LY294,002 (10 $\mu \mathrm{M})$. pSBE transcriptional activity, as measured by the luciferase assay, was significantly decreased $\left({ }^{* *} \mathrm{p}<0.01\right)$ only when PI3K was inhibited. Results represent the averages \pm SEM from 5 or more independent experiments conducted in triplicate. c GFAP-luciferase was transfected with DN constructs as in a. DN Ras did not affect
GFAP promoter activity in response to BMP2, while DN PKB showed a trend that was not significant towards decreased GFAP transcriptional activity. Cotransfection of GFAP with both DN Ras and DN PKB led to a statistically significant $\left({ }^{*} p<0.05\right)$ decrease in GFAP transcriptional activity following BMP2 treatment. Results are the averages \pm SEM of 4 or more independent experiments performed in triplicate and normalized to control values. $\mathbf{d}$ To confirm expression of transfected constructs, NCM1 cells were transfected with GFP-tagged DN Ras, Flag-tagged DN Smad1 or Smad5, DN PKB or left untransfected. Cells were fixed after $24 \mathrm{~h}$ and staining was performed using an anti-GFP antibody to recognize DN Ras, anti-Flag to recognize DN Smad1 or Smad5, or an antibody recognizing total PKB. Expression of DN $\mathrm{PKB}$ was inferred by the cytoplasmic, punctate staining for PKB seen in transfected cells (box labeled DN) that was not seen in nontransfected cells. 
Fig. 3. Inhibition of $\mathrm{PI} 3 \mathrm{~K}$ and MEK1/2/ ERK pathways reduces cytosolic phosphoSmad1/5/8. NCM1 cells were treated or not with inhibitors of the PI3K and MEK1/2/ ERK pathways followed by BMP2 exposure for $30 \mathrm{~min}$. Cytoplasmic and nuclear fractions were extracted and immunoblotting performed against phosphorylatedSmad1/5/8 (P-Smad1/5/8) (a). Top panel shows P-Smad1/5/8. $\beta$-Actin was used as a loading control (bottom). b Quantification of normalized phosphorylatedSmad1/5/8 values from three independent immunoblotting experiments. Inhibition of kinase pathways led to a significant decrease in the cytosolic pool of phosphorylated Smads $\left({ }^{*} \mathrm{p}<0.05\right)$ with no effect on the amount of phosphorylated Smads in the nucleus.

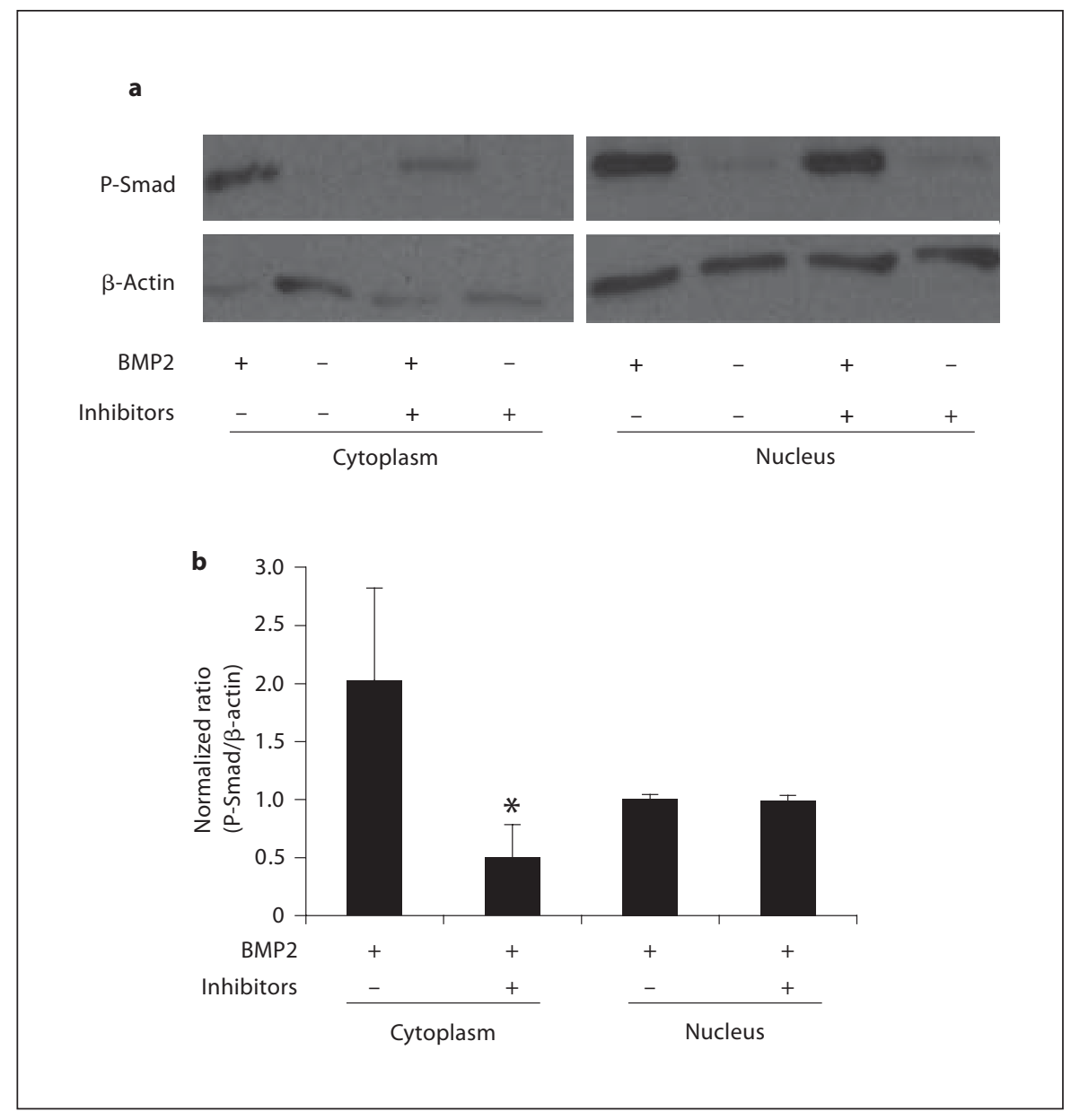

We also examined the effect of the DN proteins on BMP2 induction of the GFAP promoter. The DN PKB did not have a significant effect on the BMP2 induction of the GFAP promoter, although there was a noticeable trend toward decreased activity (fig. 2c). This may reflect the same regulation of Smad interactions as seen for the SBE promoter, with the smaller effect accounted for by the limited role for Smads in GFAP induction (fig. 1). Inactivation of the Ras pathway with DN Ras had no effect on BMP2-dependent GFAP activity, but interestingly, cotransfection of both DN PKB and DN Ras significantly reduced BMP2-induced activation of the GFAP promoter (fig. 2c). This suggests that the Ras pathway may collaborate with $\mathrm{PI} 3 \mathrm{~K}$ signaling to mediate the BMP response and supports our previous findings using pharmacological inhibitors of these pathways [18]. Expression of transfected constructs was confirmed using immunostaining against Ras-GFP, flag-tagged Smad1 or Smad5, DN PKB or endogenous PKB (fig. 2d).

\section{Inhibition of PI3K and Ras Alters Smad \\ Phosphorylation Patterns}

One way that kinase pathways could affect activity at Smad-sensitive promoters is by influencing Smad phosphorylation or nuclear localization. We previously demonstrated that BMP2 treatment of NCM1 cells resulted in movement of Smad1 to the nucleus [18]. We therefore examined the effect of PI3K and MEK1/2/ERK kinases in regulating BMP2-dependent Smad dynamics by using Western analysis to examine phospho-Smad (P-Smad) localization in cytoplasmic and nuclear fractions. NCM1 cultures were treated with or without BMP2 in the presence or absence of pharmacological inhibitors of the PI3K (LY294,002) and MEK1/2/ERK (PD98,059) pathways. Western blots were probed with antibodies recognizing P-Smad $1 / 5 / 8$ or $\beta$-actin (fig. 3a) and results were averaged across multiple experiments (fig. 3b). We found very low levels of P-Smad in the nucleus or the cytoplasm in the absence of BMP2, with a large increase in both com- 
partments following a 30-min treatment. Smad phosphorylation takes place in the cytoplasm, thus the nuclear localization confirms that nuclear translocation takes place following BMP2 treatment. There was a significant decrease in the level of cytoplasmic P-Smad in the presence of the kinase inhibitors. Interestingly, this same treatment had little effect on the level of nuclear P-Smads. These data suggest that the PI3K and/or the MEK1/2/ ERK pathways promote early Smad phosphorylation, which, over time, could contribute to BMP2-mediated transcriptional responses.

\section{Regulation of Endogenous GFAP Expression}

Since PI3K and MEK1/2/ERK signaling contribute to the BMP2-dependent activity of the GFAP promoter in a luciferase reporter system, we went on to ask whether these pathways are important for regulating expression of the endogenous GFAP gene. NCM1 cells were treated for $24 \mathrm{~h}$ with BMP2 in the absence or presence of increasing concentrations of the PI3K inhibitor LY294,002 and the MEK1/2 inhibitor PD98,059. Previous experiments demonstrated that these inhibitor concentrations were not toxic to NCM1 cells [18]. BMP2 led to a robust induction of endogenous GFAP mRNA (fig. $4 \mathrm{a}$ ) and the kinase inhibitors reduced this expression in a dose-dependent manner.

Given the absence of Smad consensus sites in the GFAP promoter, we asked whether indirect effects involving activation of other genes contribute to the induction of the endogenous GFAP promoter by BMP2. We treated NCM1 cells with the translational inhibitor cycloheximide (CHX) to determine if there was a requirement for de novo protein synthesis in regulating GFAP expression in response to BMP2. In the absence of the inhibitor, BMP2 significantly induced GFAP mRNA. Addition of $100 \mathrm{ng} /$ $\mathrm{ml}$ of $\mathrm{CHX}$ reduced BMP induction of GFAP to control levels (fig. $4 \mathrm{~b}$ ), suggesting a requirement for new protein synthesis in the BMP-dependent regulation of the GFAP promoter.

\section{BMP2 Selectively Regulates Immediate Early Genes in}

\section{NCM1 Cells}

One mechanism by which BMPs could act indirectly to promote GFAP expression would be to induce immediate early genes that would act at GFAP promoter sites. BMPs use both Sp1 and immediate early genes that comprise the AP1 complex to regulate gene expression and tissue-type differentiation during development [48-50], and we have recently identified Sp1 and AP1 consensus sequences within the region of the GFAP promoter re-

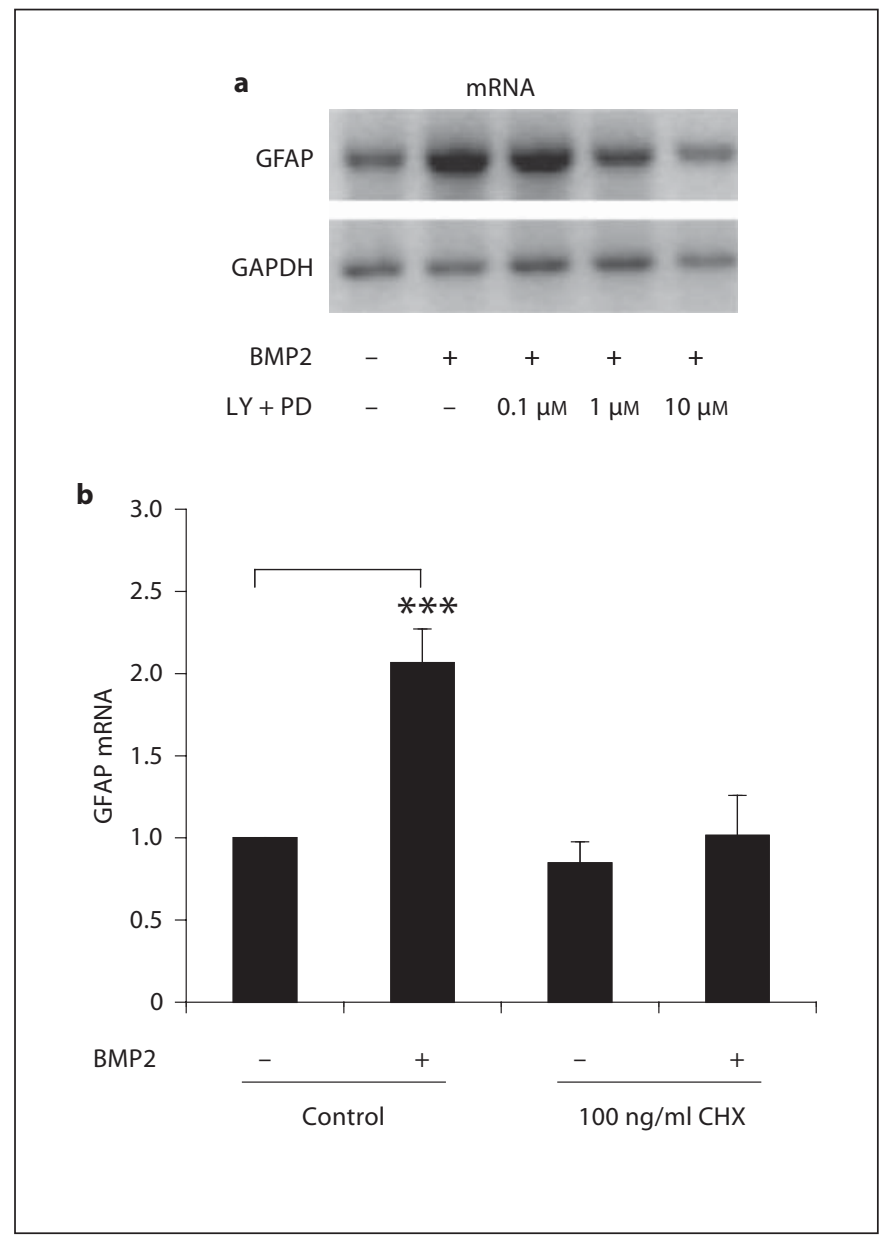

Fig. 4. BMP2-dependent regulation of endogenous GFAP expression involves PI3K and Ras signaling pathways and requires protein synthesis. a NCM1 cells were treated with the PI3K inhibitor LY294,002 (LY) and the MEK1/2/ERK inhibitor PD98,059 (PD). Addition of $10 \mathrm{ng} / \mathrm{ml} \mathrm{BMP} 2$ led to robust induction of GFAP mRNA after $24 \mathrm{~h}$ that was reduced in a dose-dependent manner by the PI3K and MEK1/2 inhibitors. b To determine if protein synthesis was required for BMP-dependent GFAP activity, NCM1 cells were treated with BMP2 in the presence or absence of the translational inhibitor cycloheximide (CHX, $100 \mathrm{ng} / \mathrm{ml})$. BMP2 led to a significant increase in GFAP expression $\left({ }^{* *} \mathrm{p}<0.001\right)$ that was abolished by cyclohexamide treatment.

quired for BMP induction [18]. We therefore asked whether Sp1 and immediate early genes were regulated by BMP2 by examining the expression of mRNAs for multiple immediate early genes and the transcription factor Sp1 in NCM1 cells. BMP2 treatment over $24 \mathrm{~h}$ did not alter expression of JunB or Fra2 mRNA (fig. 5a). Over the same period, c-Jun and fosB mRNA levels decreased modestly (fig. 5b). In contrast, Sp1 mRNA levels rose steadily over 


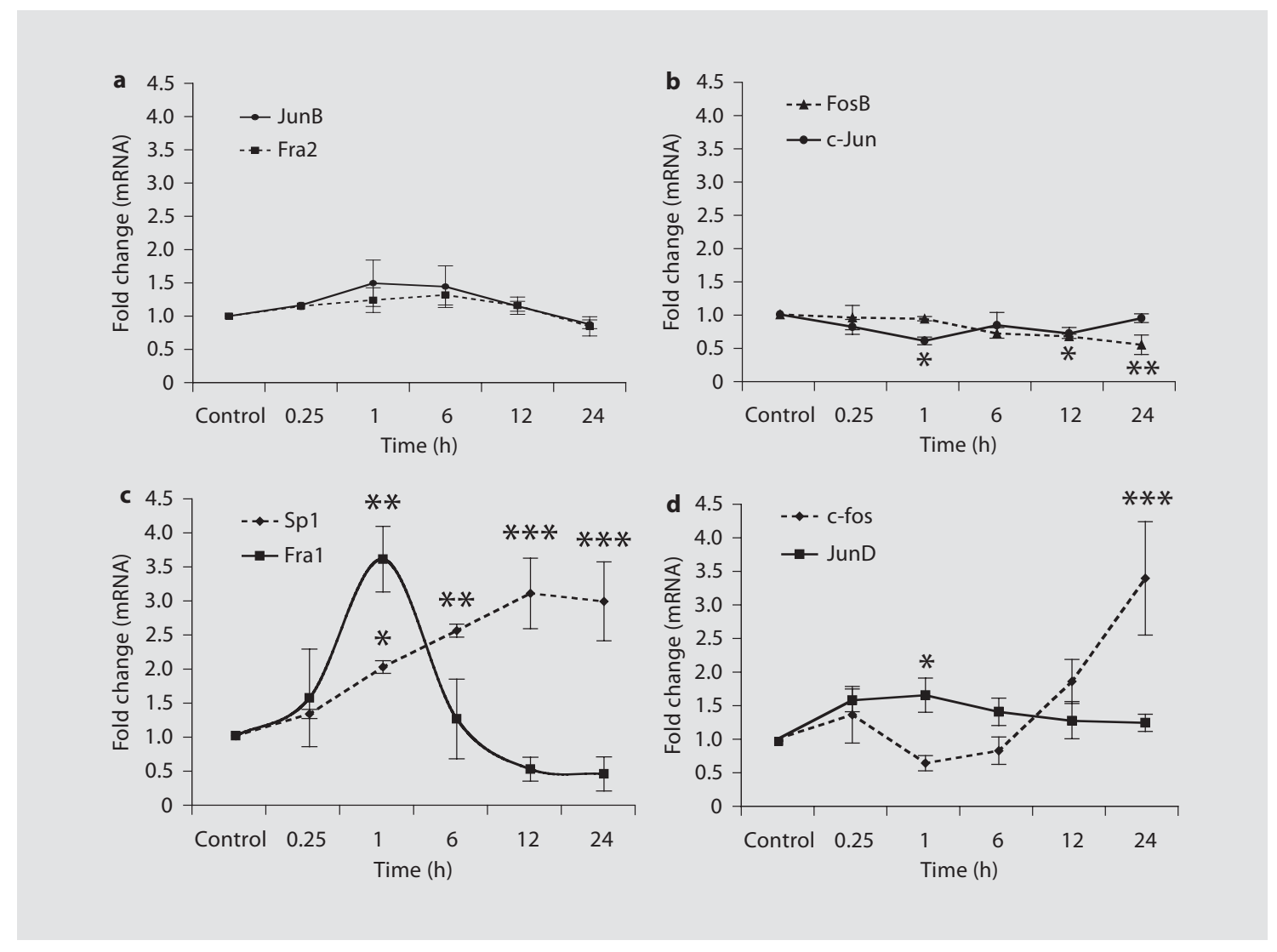

Fig. 5. BMP2 selectively induces immediate early genes. NCM1 cells were treated for $24 \mathrm{~h}$ with BMP2. Cells were harvested at the indicated time points and mRNA was reverse-transcribed and analyzed by RT-PCR using primers for a variety of immediate early genes. Fra 2 and JunB showed minimal regulation over $24 \mathrm{~h}$ in the presence of BMP2 (a), whereas c-Jun and FosB were significantly inhibited at $6 \mathrm{~h}$ and 12 and $24 \mathrm{~h}$, respectively (b). In contrast, Sp1 mRNA increased steadily over $24 \mathrm{~h}$, with expression highest at the end of the treatment period, while Fral expression peaked at $1 \mathrm{~h}$, then rapidly declined (c). c-fos exhibited a marked, delayed induction, beginning at $6 \mathrm{~h}$, while JunD increased significantly $1 \mathrm{~h}$ after treatment with a return to baseline levels after $24 \mathrm{~h}(\mathbf{d})\left({ }^{*} \mathrm{p}<0.05,{ }^{* *} \mathrm{p}<0.01,{ }^{* * *} \mathrm{p}<0.001\right)$. the 24-hour treatment period, increasing approximately 3 -fold compared to control conditions while Fral peaked after $6 \mathrm{~h}$ with a subsequent decline in expression (fig. $5 \mathrm{c}$ ). JunD mRNA increased significantly at $1 \mathrm{~h}$ then steadily declined until $24 \mathrm{~h}$ (fig. 5d). Interestingly, c-fos mRNA levels did not begin to increase until $6 \mathrm{~h}$ after BMP2 addition and then increased more than 3 -fold between 6 and $24 \mathrm{~h}$ (fig. 5d). These data suggest that BMP2 initiates a complex pattern of gene expression with both early and late expression of immediate early genes.

Given the presence of the Sp1 consensus site in the GFAP promoter and the increased expression of Sp1 mRNA, we used Western analysis to examine changes in the level of Sp1 protein over the 24-hour time course and compared it to the induction of GFAP protein over the same period (fig. 6a). Quantification across multiple experiments showed that Sp1 protein significantly increased following a 6-hour exposure to BMP2 (fig. 6b). This demonstrates a lag between mRNA induction and protein induction, since a significant increase in Sp1 mRNA was seen after $1 \mathrm{~h}$ of treatment (fig. 5c). Interestingly, although Sp1 mRNA levels continued to increase after $6 \mathrm{~h}, \mathrm{Sp} 1$ protein levels exhibited maximal induction at $6 \mathrm{~h}$ with a subsequent decline to control levels at $24 \mathrm{~h}$. This pattern of regulation suggests that modifications and/or subsequent degradation of the Sp1 protein may regulate its intracellular activity. The increase in Sp1 protein was followed by an increase in GFAP protein expression, which was visible on Western blots following a 6-hour BMP2 treatment, and significant at $12 \mathrm{~h}$ of treat- 


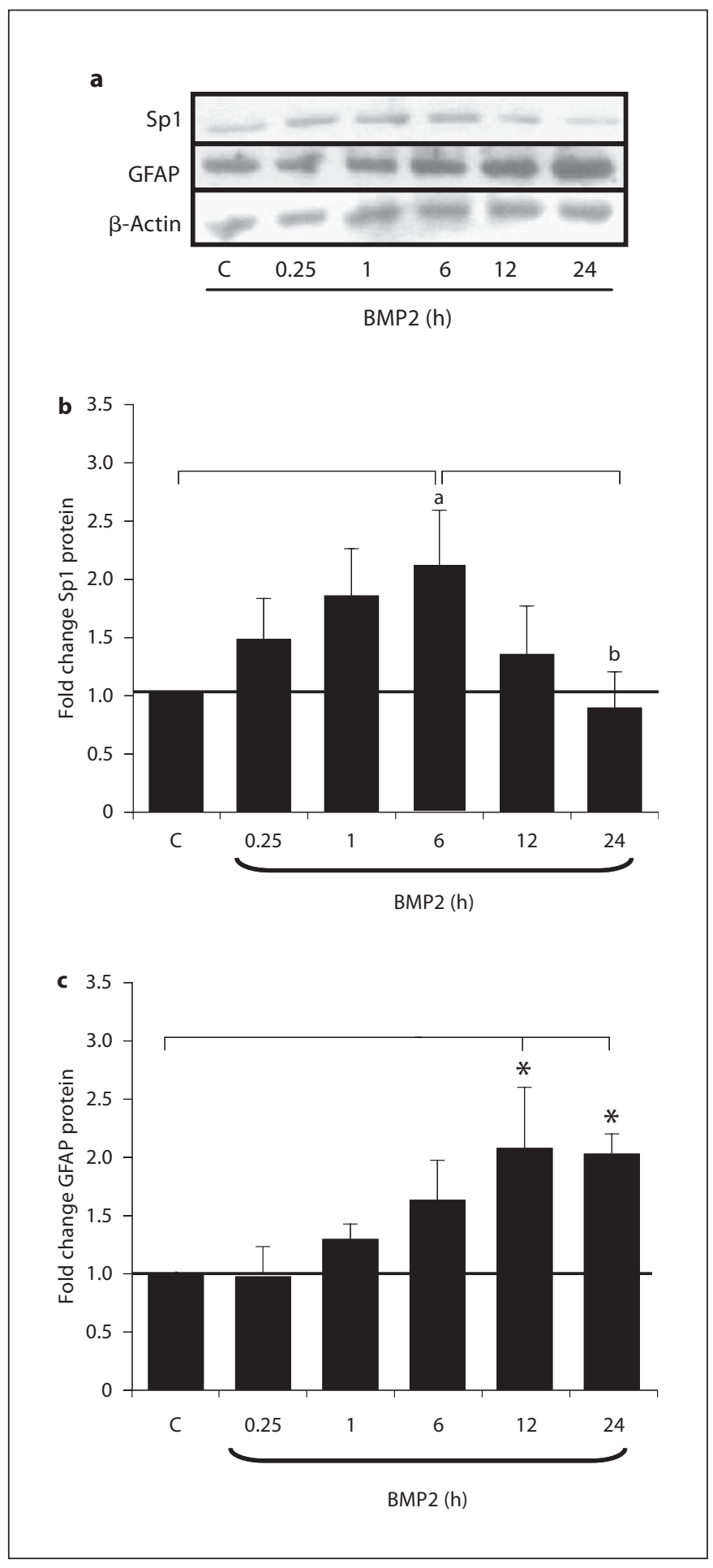

Fig. 6. BMP2 regulates GFAP and Sp1 protein expression. NCM1 cells were treated with BMP2 for the indicated times and wholecell lysates extracted and immunoblotted using Sp1 or GFAP polyclonal antibodies. $\mathrm{C}=$ Control. a Representative immunoblots showing changes in Sp1 and GFAP protein over the course of $24 \mathrm{~h}$ of BMP2 treatment. b Sp1 protein expression increased following BMP2 treatment, peaking at $6 \mathrm{~h}$ followed by a steady ment (fig. 6c). While the initial increase in GFAP protein level was correlated with the initial rise in Sp1 protein, GFAP protein remained high, even after Spl levels decreased. Thus, the induction and maintenance of GFAP by BMPs may involve temporal changes in the expression patterns of additional immediate early genes such as Fra1, JunD and possibly c-fos in addition to the transcription factor Sp1.

\section{Contribution of AP1 and Sp1 to GFAP Activation}

We previously identified adjacent AP1 and Sp1 consensus sites within a 500-bp region of the GFAP promoter required for BMP2-mediated induction (fig. 7a) [18]. Since BMP2 induced expression of transcription factors that bind to these sites, we investigated whether these interactions contributed to the regulation of the GFAP promoter. We performed site-directed mutagenesis of the GFAP promoter (fig. 7b) followed by analysis of basal and BMP2-induced activity of the wild type, AP1 and Sp1 mutants, or a double mutant using luciferase assays. Mutation of the Sp1 site resulted in a significant increase in the basal, uninduced activity of the promoter (fig. 7c). Promoter activity was even greater following BMP2 treatment, although there was a small decrease in the fold induction compared to the control construct (fold induction: GFAP-Luc $2.87 \pm 0.15$-fold; $\Delta$ Sp1GFAP-Luc $2.22 \pm 0.12$-fold; $\Delta$ Sp1GFAP-Luc significantly different from GFAP-Luc, $\mathrm{p}<0.01$ ). We did not observe a significant increase in baseline activity for the adjacent AP1 site mutation, although induction with BMP2 indicates the presence of additional activator sites in the GFAP promoter. These data suggest that a transcriptional repressor normally occupies the Sp1 site and that mutation of the Sp1 site prevents repressor binding and increases basal activity, possibly due to increased availability of the adjacent AP1 site. Displacement of this repressor may involve increased levels of Sp1 protein following BMP2 treatment, permitting GFAP transcriptional activation from activator sites that might include the normally occluded AP1 site. 
Fig. 7. Sp1 and AP1 promoter sequences contribute to GFAP transcriptional activation. a Schematic depicting the GFAP promoter sequence from -1501 to -1261 . Underlined, numbered sequences depict putative transcription factor binding sites including AP1 (1), Sp1 (2), Stat (3) and a glucocorticoid-responsive element (4). b Sequences of promoter constructs generated using site-directed mutagenesis. Alterations in AP1 and Sp1 consensus sites were generated that introduced four basepair substitutions into the promoter sequence of the full-length GFAP promoter. c NCM1 cells were transfected with wildtype GFAP or GFAP with the Sp1 mutation, the AP1 mutation or a double mutant and assayed for gene activity after $24 \mathrm{~h}$ of BMP2 treatment ( ${ }^{\mathrm{a}} \mathrm{p}<0.05$ compared to control, ${ }^{\mathrm{b}} \mathrm{p}<0.05$ compared to nonmutated control, ${ }^{\mathrm{c}} \mathrm{p}=0.0001$ compared to nonmutated BMP2 treated, ${ }^{\mathrm{d}} \mathrm{p}<0.001$ compared to control, Sp1 mutant). All values represent the combined averages \pm SEM from 5 or more independent experiments, performed in triplicate and normalized to pRL-TK luciferase (Luc) values. RLU = Arbitrary relative light units. a

-1501 actcaccttggcatagacataatggtcaggggcgggcacacagctgattccegctgcac 12

1441 tccaggccccttcaatgctttccgagaagtccattgagctgggagcttgtactgcacca 3

1381 agggctgacatcctggcagccagggatgaaagcagcccatggggetaccettgccgtatg

1321 cctcactggcggcagagaacaaggctctattcagcaaatacctggagtagacaccagaa 4

b

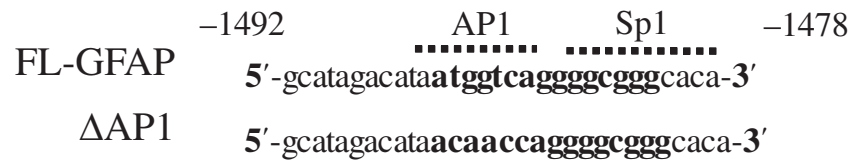

$\Delta \mathrm{Sp} 1 \quad \mathbf{5}^{\prime}$-gcatagacataatggtcaggatatggcaca-3'

c

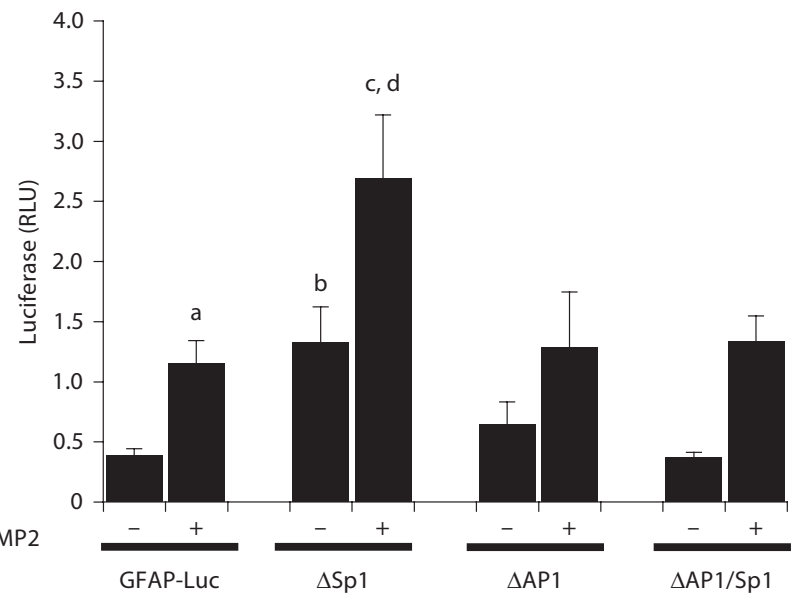

While the Sp1 mutation increases basal activity, this increase is not seen for the Sp1, AP1 double mutant. In the absence of both functional Sp1 sites and AP1 sites, there is no longer any repression or activation from those sites, permitting induction by way of BMP-dependent activation of additional site(s). This suggests that while the increase in Sp1 protein following BMP2 treatment plays a role in displacing a repressor protein(s), in the absence of repressor binding, induction is effectively mediated via other promoter sites (fig. 8). Thus, these sites contribute to a dynamic regulation of repressors and activators that mediates basal and BMP-dependent activation of the GFAP promoter.

\section{Discussion}

One way to understand the differing effects of BMPs on neuronal and glial development is to define the intracellular pathways that are involved in cell-specific gene expression. We have examined the consequences of BMP signaling on the expression of a glial-specific gene in a peripheral glial cell line and shown that the PI3K and MEK1/2/ERK pathways, in addition to the canonical Smad pathway, contribute to induction of the GFAP promoter by BMP2. Comparison of the complex GFAP promoter to a promoter consisting solely of Smad 
Fig. 8. BMPs signal through Smad, PI3K and Ras pathways to regulate GFAP expression. Signaling diagram depicting the actions of the PI3K and Ras pathways on Smad signaling and downstream activation of the GFAP promoter. The kinase pathways regulate the extent of Smad activation and may influence the relative localization of cytosolic and nuclear phosphorylated Smads. BMPs, possibly through the actions of these nuclear Smads, induce the expression of early transcription factors. These transcription factors include immediate early genes (IEG) and Sp1 which bind consensus sequences in the GFAP promoter. In this model, the BMP-dependent increase in Sp1 protein causes the displacement of a transcriptional repressor that binds in the region of the Sp1/AP1 sites, permitting binding of transcriptional activators such as AP1. Together with the binding of another BMP-dependent transcriptional activator protein $(\mathrm{X})$ at an additional site, these interactions result in BMP induction of the GFAP promoter. This model suggests that multiple converging pathways drive the induction of the GFAP promoter by BMP 2 and is consistent with partial induction of the promoter following inhibition of the PI3K, MEK1/2/ERK pathways or Smad signaling. It also fits with results from mutational analysis showing increased basal expression for the Sp1 site mutation and continued BMP-induced activity for the Sp1/AP1 double mutant.

consensus sites [33] has shown that Smad and non-Smad pathways contribute differentially to the BMP-dependent activity. We show that BMP-dependent gene expression is regulated at multiple levels that include $\mathrm{ki}$ nase-dependent regulation of cytoplasmic Smad activation, regulation of immediate early gene expression, and promoter interactions. These findings contribute to a growing body of evidence that identifies a diverse range of downstream effectors for BMPs and other TGF- $\beta$ family members $[2,26,27,29,51-53]$. The timing and correct balance of activation of these pathways are likely to determine critical developmental decisions including the regulation of peripheral neuronal and glial cell fates.

BMP receptor activation leads to nuclear accumulation of phosphorylated Smad1/5 and assembly of an active promoter complex consisting of Smads and associated transcriptional activators [54]. Thus, it was not surprising that BMP2 strongly induced the activity of a synthetic promoter consisting of repeated Smad consensus sites [32, 33]. BMP2 also induced activity of the glialspecific GFAP promoter despite a lack of known Smad consensus sites within the sequence [18]. This suggested either an indirect effect of Smads, or the actions of a

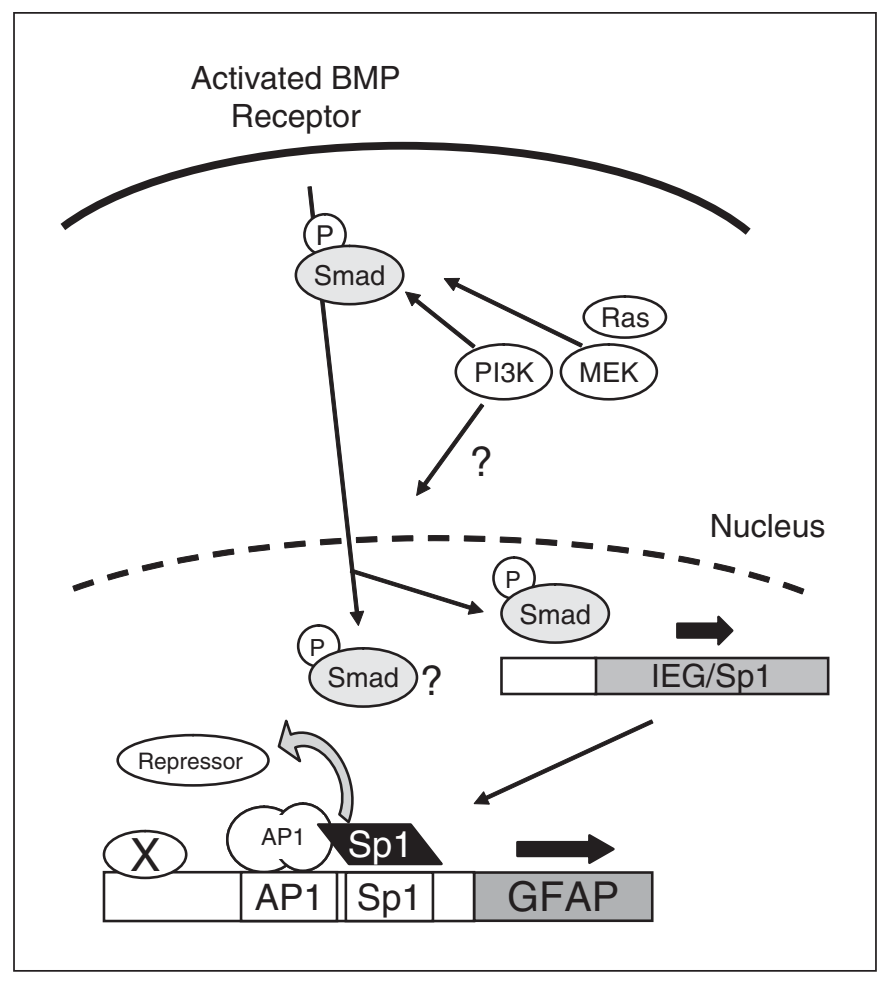

Smad-independent pathway in the BMP-dependent regulation of the GFAP promoter. Inhibition of Smad signaling via expression of DN Smad proteins resulted in a partial, but significant reduction in BMP-induced activity at the GFAP promoter, suggesting that both of these mechanisms, indirect effects of Smad activation and Smad-independent signaling, contribute to activation. In contrast, inhibition of Smad signaling resulted in the almost complete inhibition of BMP2-dependent activation of the pSBE promoter, demonstrating that Smad signaling can differentially contribute to the activity of different BMP responsive promoters.

Intracellular kinases are known effectors of BMP signaling in a number of systems and may act to modulate the effects of BMPs in a cell type-specific manner [2, 23$25,27]$. We found that the PI3K and MEK $1 / 2 /$ ERK pathways promoted BMP signaling in our peripheral glial cell line for both the Smad-binding pSBE and the GFAP promoters. Recent studies have demonstrated that intracellular kinase pathways can interact with and directly influence the Smad-signaling pathways $[29,55,56]$. Enhancement of Smad signaling via the MEK1/2/ERK pathway has been observed in glomerular mesangial cells [29], while MEK1/2/ERK signaling exerts an inhibitory 
effect on Smad activity in epithelial cells [56]. The variety of different responses reported suggests that interactions between these pathways take place in a cell-type-specific manner. Our data shows that inhibition of PI3K and MEK1/2/ERK signaling in a glial cell line partially blocked BMP-dependent activity of both the SBE and GFAP promoters, suggesting that the actions of these kinase pathways regulate gene activity in a cell-type-, but not promoter-specific manner.

In contrast to the partial effects of PI3K and MEK $1 / 2 /$ ERK kinase inhibition at both promoters, abolishing Smad signaling completely blocked BMP-dependent activity of the SBE promoter while only partially inhibiting GFAP promoter activity. This is consistent with a scenario in which Smad signaling is modulated by these kinase pathways, promoting activation at the Smad-dependent SBE promoter and, to a lesser extent, at the partially Smad-regulated GFAP promoter. One way that the PI3K and MEK1/2/ERK pathways could act to globally modulate the actions of Smads at the SBE and GFAP promoters is by regulating Smad activation or translocation. We provide evidence that inhibition of the PI3K and MEK1/2/ERK pathways affects the level of cytosolic phosphorylated Smads following BMP treatment, suggesting that these kinases normally promote Smad phosphorylation upon BMP receptor binding. Interestingly, kinase inhibition did not affect the level of nuclear-localized phospho-Smad following a 30-min treatment with BMP2. This finding raises the possibility that the PI3K and MEK1/2/ERK pathways also influence the dynamics of nuclear shuttling of phosphorylated Smads either by limiting nuclear translocation or promoting movement from the nucleus to the cytoplasm [47]. However, further studies are needed to determine the effects of kinase signaling on the timing of Smad transport and on the relative contributions of nuclear import and export.

Once in the nucleus, phosphorylated Smads could promote gene expression via direct binding to Smad-responsive promoter elements, indirect interactions with the promoter, or by induction of transcription factors that indirectly control gene expression. Loss of GFAP induction by BMP2 in cycloheximide-treated cells, along with the absence of identifiable Smad consensus sites, suggests that Smad-dependent induction involves additional gene products. We have shown that Sp1 and a number of immediate early genes are induced by BMP2, including components of the AP1 complex. This suggests future studies to determine whether PI3K and MEK1/2/ERK signaling contributes to the regulation of these genes, and led us to question whether these early BMP-inducible genes contribute to the regulation of GFAP promoter.

Mutational analysis of the Sp1 and AP1 sites within the GFAP promoter suggests that these regulators contribute to the regulation of basal and BMP2-induced activity of the GFAP promoter. The pattern of promoter activation for the Spl mutant suggests that, under control conditions, a transcriptional repressor binds at the Sp1 site and occludes binding of the AP1 activator complex. In the presence of BMP2, this repressor is partially displaced, possibly as a result of increased Sp1 expression. This permits induction of the gene via the binding of activator proteins to multiple sites that may include the adjacent AP1 site. When the Sp1 site is mutated, AP1 can bind under control conditions, resulting in a higher baseline level of promoter activity. Treatment with BMP2 leads to activation from the additional site(s), resulting in a further induction. This maximal induction is not entirely additive, resulting in a modest decrease in the fold induction, even though overall expression levels are higher. Mutation of the AP1 site does not significantly affect baseline control transcription since the site is normally occluded under these conditions. Following BMP2 treatment, there is a trend toward increased expression that does not reach significance, consistent with partial induction from the additional, non-AP1 site. In the double mutant, protein binding to the Sp1 site does not occlude the AP1 site, but the AP1 mutation prevents AP1 binding with the result of normal basal expression and BMP2 induction involving the additional sites. This model (fig. 8) is consistent with studies showing that transcriptional repressors regulate Spl promoter binding and activity during regulation of myogenic cell proliferation and motor neuron development $[57,58]$. Together, these data begin to define complex regulatory interactions at the GFAP promoter in which competition for promoter binding by activators and repressors, and the action of multiple activator interactions dynamically regulate cell type-specific GFAP expression.

The idea that competition between promoter-binding factors can contribute to the regulation of cell-type-specific gene expression has been suggested for Smad regulation of neuron and glial development in the central nervous system [59] and is consistent with a previously identified role for $\mathrm{Sp1}$ in regulating distinct steps in lineage commitment during glial differentiation [60,61]. The presence of the occluded AP1 activator site as well as additional BMP-dependent sites in the GFAP promoter suggests that the expression of different activator and repres- 
sor proteins in specific cells types at precise developmental stages could drive the expression of lineage-specific patterns of gene expression during nervous system development. This could result in cell type specificity of BMP action during the differentiation and maturation of distinct PNS lineages.

\section{Acknowledgements}

We thank Wyeth Pharmaceuticals for providing recombinant BMP2 and Tatyana Pozharskaya for technical assistance. This work was supported by NIH HD042716 to S.J.B., NIH F31 NS48661 to J.J.D., and by a grant for Core Facilities for Neuroscience at Brandeis P30 NS45713.

\section{References}

1 Schmitt B, Ringe J, Haupl T, Notter M, Manz R, Burmester GR, Sittinger M, Kaps C: BMP2 initiates chondrogenic lineage development of adult human mesenchymal stem cells in high-density culture. Differentiation 2003; 71:567-577.

12 Ghosh-Choudhury N, Abboud SL, Mahimainathan L, Chandrasekar B, Choudhury GG: Phosphatidylinositol 3-kinase regulates bone morphogenetic protein-2 (BMP-2)-induced myocyte enhancer factor 2A-dependent transcription of BMP-2 gene in cardiomyocyte precursor cells. J Biol Chem 2003; 278:21998-22005.

-3 Chalazonitis A, D’Autreaux F, Guha U, Pham TD, Faure C, Chen JJ, Roman D, Kan L, Rothman TP, Kessler JA, Gershon MD: Bone morphogenetic protein-2 and -4 limit the number of enteric neurons but promote development of a trkC-expressing neurotrophin-3-dependent subset. J Neurosci 2004;24: 4266-4282.

4 Chang MY, Son H, Lee YS, Lee SH: Neurons and astrocytes secrete factors that cause stem cells to differentiate into neurons and astrocytes, respectively. Mol Cell Neurosci 2003; 23:414-426.

5 Bonaguidi Ma, McGuire T, Hu M, Kan L, Samanta J, Kessler JA: LIF and BMP signaling generate separate and discrete types of GFAP-expressing cells. Development 2005; 132:5503-5514.

6 Gomes WA, Mehler MF, Kessler JA: Transgenic overexpression of BMP4 increases astroglial and decreases oligodendroglial lineage commitment. Dev Biol 2003;255: 164-177.

7 Cheng X, Wang Y, He Q, Qiu M, Whittemore SR, Cao Q: Bone morphogenetic protein signaling and OLIG1/2 interact to regulate the differentiation and maturation of adult oligodendrocyte precursor cells. Stem cells (Dayton, Ohio) 2007;25:3204-3214.

-8 Grinspan JB, Edell E, Carpio DF, Beesley JS, Lavy L, Pleasure D, Golden JA: Stage-specific effects of bone morphogenetic proteins on the oligodendrocyte lineage. J Neurobiol 2000;43:1-17.

-9 See J, Mamontov P, Ahn K, Wine-Lee L, Crenshaw EB 3rd, Grinspan JB: BMP signaling mutant mice exhibit glial cell maturation defects. Mol Cell Neurosci 2007;35:171-182.
0 See J, Zhang X, Eraydin N, Mun SB, Mamontov P, Golden JA, Grinspan JB: Oligodendrocyte maturation is inhibited by bone morphogenetic protein. Mol Cell Neurosci 2004; 26:481-492.

11 Lo L, Sommer L, Anderson DJ: MASH1 maintains competence for BMP2-induced neuronal differentiation in post-migratory neural crest cells. Curr Biol 1997;7:440450.

12 Lo L, Tiveron MC, Anderson DJ: MASH1 activates expression of the paired homeodomain transcription factor Phox $2 \mathrm{a}$, and couples pan-neuronal and subtype-specific components of autonomic neuronal identity. Development 1998;125:609-620.

13 Bixby S, Kruger GM, Mosher JT, Joseph NM, Morrison SJ: Cell-intrinsic differences between stem cells from different regions of the peripheral nervous system regulate the generation of neural diversity. Neuron 2002;35: 643-656.

14 Faure C, Chalazonitis A, Rheaume C, Bouchard G, Sampathkumar SG, Yarema KJ, Gershon MD: Gangliogenesis in the enteric nervous system: roles of the polysialylation of the neural cell adhesion molecule and its regulation by bone morphogenetic protein4. Dev Dyn 2007;236:44-59.

15 Pisano JM, Birren SJ: Restriction of developmental potential during divergence of the enteric and sympathetic neuronal lineages. Development 1999;126:2855-2868.

16 Pisano JM, Colon-Hastings F, Birren SJ: Postmigratory enteric and sympathetic neural precursors share common, developmentally regulated, responses to BMP2. Dev Biol 2000;227:1-11.

17 Sarkar AA, Howard MJ: Perspectives on integration of cell extrinsic and cell intrinsic pathways of signaling required for differentiation of noradrenergic sympathetic ganglion neurons. Auton Neurosci 2006;126-127: 225-231.

18 Dore JJ, Crotty KL, Birren SJ: Inhibition of glial maturation by bone morphogenetic protein 2 in a neural crest-derived cell line. Dev Neurosci 2005;27:37-48.
19 Yew KH, Hembree M, Prasadan K, Preuett B, McFall C, Benjes C, Crowley A, Sharp S, Tulachan S, Mehta S, Tei E, Gittes G: Cross-talk between bone morphogenetic protein and transforming growth factor- $\beta$ signaling is essential for exendin-4-induced insulinpositive differentiation of AR42J cells. J Biol Chem 2005;280:32209-32217.

20 Tian Q, He XC, Hood L, Li L: Bridging the BMP and WNT pathways by pi3 kinase/AKT and 14-3-3५. Cell Cycle 2005;4:215-216.

21 Osyczka AM, Leboy PS: Bone morphogenetic protein regulation of early osteoblast genes in human marrow stromal cells is mediated by extracellular signal-regulated kinase and phosphatidylinositol 3-kinase signaling. Endocrinology 2005; 146:3428-3437.

22 Kraunz KS, Nelson HH, Liu M, Wiencke JK, Kelsey KT: Interaction between the bone morphogenetic proteins and Ras/MAP-kinase signalling pathways in lung cancer. $\mathrm{Br} \mathrm{J}$ Cancer 2005;93:949-952.

23 Suzawa M, Tamura Y, Fukumoto S, Miyazono K, Fujita T, Kato S, Takeuchi Y: Stimulation of Smad1 transcriptional activity by Ras-extracellular signal-regulated kinase pathway: A possible mechanism for collagen-dependent osteoblastic differentiation. J Bone Miner Res 2002;17:240-248.

24 Xu RH, Dong Z, Maeno M, Kim J, Suzuki A, Ueno N, Sredni D, Colburn NH, Kung HF: Involvement of Ras/Raf/AP-1 in BMP-4 signaling during Xenopus embryonic development. Proc Natl Acad Sci USA 1996;93:834838.

25 Yue J, Frey RS, Mulder KM: Cross-talk between the Smad1 and Ras/MEK signaling pathways for TGF $\beta$. Oncogene 1999;18: 2033-2037.

26 Ghosh-Choudhury N, Abboud SL, Chandrasekar B, Ghosh Choudhury G: BMP-2 regulates cardiomyocyte contractility in a phosphatidylinositol 3 kinase-dependent manner. FEBS Lett 2003;544:181-184.

27 Ghosh-Choudhury N, Abboud SL, Nishimura R, Celeste A, Mahimainathan L, Choudhury GG: Requirement of BMP-2-induced phosphatidylinositol 3-kinase and AKT serine/threonine kinase in osteoblast differentiation and Smad-dependent BMP-2 gene transcription. J Biol Chem 2002;277:3336133368. 
28 Remy I, Montmarquette A, Michnick SW: PKB/Akt modulates TGF- $\beta$ signalling through a direct interaction with Smad3. Nature Cell Biology 2004;6:358-365.

-29 Hayashida T, Decaestecker M, Schnaper HW: Cross-talk between ERK MAP kinase and Smad signaling pathways enhances tgfbeta-dependent responses in human mesangial cells. FASEB J 2003;17:1576-1578.

>30 Fukuda S, Taga T: Cell fate determination regulated by a transcriptional signal network in the developing mouse brain. Anat Sci Int 2005;80:12-18.

-31 Takizawa T, Ochiai W, Nakashima K, Taga T: Enhanced gene activation by Notch and BMP signaling cross-talk. Nucleic Acids Res 2003;31:5723-5731

-32 Krohn K, Rozovsky I, Wals P, Teter B, Anderson CP, Finch CE: Glial fibrillary acidic protein transcription responses to transforming growth factor- $\beta 1$ and interleukin- $1 \beta$ are mediated by a nuclear factor-1-like site in the near-upstream promoter. J Neurochem 1999; 72:1353-1361.

>33 Jonk LJ, Itoh S, Heldin CH, ten Dijke P, Kruijer W: Identification and functional characterization of a Smad binding element (SBE) in the junB promoter that acts as a transforming growth factor- $\beta$, activin, and bone morphogenetic protein-inducible enhancer. J Biol Chem 1998;273:21145-21152.

-34 Feig LA, Cooper GM: Inhibition of NIH 3T3 cell proliferation by a mutant ras protein with preferential affinity for GDP. Mol Cell Biol 1988;8:3235-3243.

- 35 Cong LN, Chen H, Li Y, Zhou L, McGibbon MA, Taylor SI, Quon MJ: Physiological role of Akt in insulin-stimulated translocation of GLUT4 in transfected rat adipose cells. Mol Endocrinol 1997;11:1881-1890.

-36 Nishimura R, Kato Y, Chen D, Harris SE, Mundy GR, Yoneda T: Smad5 and DPC4 are key molecules in mediating BMP-2-induced osteoblastic differentiation of the pluripotent mesenchymal precursor cell line C2C12. J Biol Chem 1998;273:1872-1879.

37 Lo LC, Birren SJ, Anderson DJ: V-myc immortalization of early rat neural crest cells yields a clonal cell line which generates both glial and adrenergic progenitor cells. Dev Biol 1991;145:139-153.

$\checkmark 38$ Lockhart ST, Turrigiano GG, Birren SJ: Nerve growth factor modulates synaptic transmission between sympathetic neurons and cardiac myocytes. J Neurosci 1997;17: 9573-9582.

>39 Hawrot E, Patterson PH: Long-term culture of dissociated sympathetic neurons. Methods Enzymol 1979;58:574-584.
40 Rozen S, Skaletsky H: Primer3 on the www for general users and for biologist programmers. Methods Mol Biol 2000;132:365386.

41 Nakashima K, Yanagisawa M, Arakawa H, Kimura N, Hisatsune T, Kawabata M, Miyazono K, Taga T: Synergistic signaling in fetal brain by STAT3-Smad1 complex bridged by p300. Science 1999;284:479-482.

42 Toker A, Newton AC: Akt/protein kinase B is regulated by autophosphorylation at the hypothetical PDK-2 site. J Biol Chem 2000; 275:8271-8274.

43 Kuemmerle JF, Zhou H: Insulin-like growth factor-binding protein-5 (IGFBP-5) stimulates growth and IGF-I secretion in human intestinal smooth muscle by Ras-dependent activation of p38 Map kinase and Erk1/2 pathways. J Biol Chem 2002;277:2056320571.

44 Li J, Tang MS, Liu B, Shi X, Huang C: A critical role of PI-3K/Akt/JNKs pathway in benzo[a]pyrene diol-epoxide (B[a]PDE)-induced AP-1 transactivation in mouse epidermal Cl41 cells. Oncogene 2004;23:39323944.

45 Wang FS, Wang CJ, Chen YJ, Chang PR, Huang YT, Sun YC, Huang HC, Yang YJ, Yang KD: Ras induction of superoxide activates ERK-dependent angiogenic transcription factor HIF-1 $\alpha$ and VEGF-A expression in shock wave-stimulated osteoblasts. J Biol Chem 2004;279:10331-10337.

-46 Wang Q, Somwar R, Bilan PJ, Liu Z, Jin J, Woodgett JR, Klip A: Protein kinase B/Akt participates in GLUT4 translocation by insulin in L6 myoblasts. Mol Cell Biol 1999; 19: 4008-4018.

47 Xiao Z, Watson N, Rodriguez C, Lodish HF: Nucleocytoplasmic shuttling of Smad1 conferred by its nuclear localization and nuclear export signals. J Biol Chem 2001;276:3940439410.

48 Karreth F, Hoebertz A, Scheuch H, Eferl R, Wagner EF: The AP1 transcription factor Fra2 is required for efficient cartilage development. Development 2004;131:5717-5725.

49 Peng Y, Xu RH, Mei JM, Li XP, Yan D, Kung HF, Phang JM: Neural inhibition by c-Jun as a synergizing factor in bone morphogenetic protein 4 signaling. Neuroscience 2002;109: 657-664.

50 Wach S, Schirmacher P, Protschka M, Blessing $\mathrm{M}$ : Overexpression of bone morphogenetic protein-6 (BMP-6) in murine epidermis suppresses skin tumor formation by induction of apoptosis and downregulation of fos/jun family members. Oncogene 2001 20:7761-7769.
51 Ghosh Choudhury G, Jin DC, Kim Y, Celeste A, Ghosh-Choudhury N, Abboud HE: Bone morphogenetic protein-2 inhibits MAPKdependent Elk-1 transactivation and DNA synthesis induced by EGF in mesangial cells. Biochem Biophys Res Commun 1999;258: 490-496.

52 Lai CF, Cheng SL: Signal transductions induced by bone morphogenetic protein- 2 and transforming growth factor- $\beta$ in normal human osteoblastic cells. J Biol Chem 2002;277: 15514-15522.

53 Althini S, Usoskin D, Kylberg A, Kaplan PL, Ebendal T: Blocked MAP kinase activity selectively enhances neurotrophic growth responses. Mol Cell Neurosci 2004;25:345354.

54 Itoh S, Itoh F, Goumans MJ, Ten Dijke P: Signaling of transforming growth factor- $\beta$ family members through Smad proteins. Eur J Biochem 2000;267:6954-6967.

55 Kretzschmar M, Doody J, Massague J: Opposing bmp and EGF signalling pathways converge on the TGF- $\beta$ family mediator Smad1. Nature 1997;389:618-622.

56 Kretzschmar M, Doody J, Timokhina I, Massague J: A mechanism of repression of TGF $\beta /$ Smad signaling by oncogenic Ras. Genes Dev 1999;13:804-816

57 Parakati R, DiMario JX: Dynamic transcriptional regulatory complexes, including E2F4, p107, p130, and Sp1, control fibroblast growth factor receptor 1 gene expression during myogenesis. J Biol Chem 2005;280:2128421294.

58 Lee SK, Jurata LW, Funahashi J, Ruiz EC, Pfaff SL: Analysis of embryonic motoneuron gene regulation: Derepression of general activators function in concert with enhancer factors. Development 2004;131:3295-3306.

59 Sun Y, Nadal-Vicens M, Misono S, Lin MZ, Zubiaga A, Hua X, Fan G, Greenberg ME: Neurogenin promotes neurogenesis and inhibits glial differentiation by independent mechanisms. Cell 2001;104:365-376.

60 Wei Q, Miskimins WK, Miskimins R: The Sp1 family of transcription factors is involved in p27(Kip1)-mediated activation of myelin basic protein gene expression. Mol Cell Biol 2003;23:4035-4045.

61 Wei Q, Miskimins WK, Miskimins R: Sox10 acts as a tissue-specific transcription factor enhancing activation of the myelin basic protein gene promoter by P27kipl and Sp1. J Neurosci Res 2004;78:796-802. 